\title{
Review Article \\ Photocatalysis of Titanium Dioxide for Water Disinfection: Challenges and Future Perspectives
}

\author{
M. J. Wu, ${ }^{1,2}$ T. Bak, ${ }^{2}$ P. J. O'Doherty, ${ }^{1}$ M. C. Moffitt, ${ }^{1,2}$ J. Nowotny, \\ T. D. Bailey, ${ }^{1}$ and C. Kersaitis ${ }^{1}$ \\ ${ }^{1}$ School of Science and Health, University of Western Sydney, Penrith, NSW 2751, Australia \\ ${ }^{2}$ University of Western Sydney, Solar Energy Technologies, Penrith, NSW 2751, Australia \\ Correspondence should be addressed to M. J.Wu; m.wu@uws.edu.au
}

Received 9 May 2014; Revised 18 August 2014; Accepted 25 August 2014; Published 7 September 2014

Academic Editor: Rong-Jun Xie

Copyright (C) 2014 M. J. Wu et al. This is an open access article distributed under the Creative Commons Attribution License, which permits unrestricted use, distribution, and reproduction in any medium, provided the original work is properly cited.

\begin{abstract}
The performance of metal oxides such as titanium dioxide $\left(\mathrm{TiO}_{2}\right)$, in the conversion of solar energy into chemical energy, is determined by semiconducting properties. The conversion process is closely related to the light-induced reactivity between oxide semiconductors and water, which may lead to partial water oxidation and consequently water disinfection. Key performance-related properties are considered here, including light absorption, light-induced ionisation over the band gap, charge separation, charge transport, charge transfer, and the chemical reactions taking place at anodic and cathodic sites. Optimisation of these interconnected performance-related properties is discussed, along with the photocatalytic application in water disinfection.
\end{abstract}

\section{Introduction}

Over the last decade research activities which aimed at the development of photocatalysts for water purification by photosensitive oxide materials, such as $\mathrm{TiO}_{2}$, have intensified [1-5]. The underlying concept of water purification involves the utilisation of solar energy to oxidise water molecules for the production of reactive oxygen species and other oxidising radicals, which are toxic to microorganisms in water. $\mathrm{TiO}_{2}$ has been the focus of intensive research activities due to its high photocatalytic activity under the photon energy of ultraviolet and possibly visible light, chemical and thermal stability, resistance to chemical breakdown, and strong mechanical properties. Its application in water disinfection is enhanced by the ability of $\mathrm{TiO}_{2}$ to completely destroy organic pollutants and microorganisms [6-11]. It appears, however, that most of the reported experimental data on photocatalytic water purification are not comparable, even for the same chemical systems, due to lack of reproducibility. Therefore, there is an urgent need to assess the reasons for this incompatibility. Generation of meaningful antimicrobial data may lead to derivation of theoretical models. Such models could then be used to compare photocatalytic systems and predict the effect of basic properties, such as chemical composition, structure, and semiconducting properties, on performance.

As is known to the present, oxide materials are well defined in terms of reproducibility when they are in thermodynamic equilibrium with the gas phase of controlled oxygen activity. In the case of $\mathrm{TiO}_{2}$, its properties are controlled by the conditions of the equilibrium [12]. At lower temperatures (below equilibrium) they are profoundly influenced by cooling procedures, such as cooling rate and the associated gas phase composition. In many instances, however, $\mathrm{TiO}_{2}$ specimens are processed at room temperature using soft chemistry. This results in properties being determined by the applied experimental procedures, which are frequently not reproducible.

In this review, we consider the light-induced reactivity of $\mathrm{TiO}_{2}$-based semiconductors against microorganisms in water through the formation of active radicals that exhibit a high oxidation power. The related effects are considered in terms of a range of photo-induced reactions of $\mathrm{TiO}_{2}$ with water. The reactivity between $\mathrm{TiO}_{2}$ and water is determined by the semiconducting properties and the associated charge transfer at the $\mathrm{H}_{2} \mathrm{O} / \mathrm{TiO}_{2}$ interface. The quantitative evaluation of free 
radicals, which can be employed in the development process of photocatalytic materials, is discussed. The survey of possible microorganisms in water contamination highlights microbial diversity which may have varying sensitivity to the photocatalysis-mediated water disinfection.

\section{Water Oxidation}

The concept of the conversion of solar energy into chemical energy required for water oxidation by n-type semiconductors, such as $\mathrm{TiO}_{2}$, is based on light-induced generation of electron-electron hole pairs $[12,13]$. The primary reaction of $\mathrm{TiO}_{2}$ with water is the anodic reaction, which results in a total or partial oxidation of water, depending on the number of electrons removed from water molecules.

Total water oxidation is associated with the transfer of four electrons from two water molecules leading to the formation of one molecule of oxygen $\left(\mathrm{O}_{2}\right)$ and four protons. The latter species can be reduced to hydrogen at the cathodic site. Thus, total oxidation ultimately leads to the generation of oxygen and hydrogen gas in a stoichiometric ratio.

An alternative reactivity of $\mathrm{TiO}_{2}$ with water results in partial water oxidation, which is associated with the removal of two electrons from two water molecules [13].

The partial water oxidation may be represented by the following anodic reaction:

$$
2 \mathrm{H}_{2} \mathrm{O} \longleftrightarrow 2 \mathrm{HO}^{*}+2 \mathrm{H}^{+}+2 \mathrm{e}^{\prime}
$$

where $\mathrm{e}^{\prime}$ denotes quasi-free electron in the $\mathrm{TiO}_{2}$ lattice. Alternative anodic reaction results in the formation of hydrogen peroxide and protons:

$$
2 \mathrm{H}_{2} \mathrm{O}+2 \mathrm{~h}^{\bullet} \longleftrightarrow \mathrm{H}_{2} \mathrm{O}_{2}+2 \mathrm{H}^{+}
$$

In the reaction, $\mathrm{h}^{\bullet}$ is an electron hole. The charge neutrality requires that the negative charge of $\mathrm{TiO}_{2}$, associated with the reactions (1) and (2), is removed at the cathodic site. The predominant cathodic reaction is based on reduction of oxygen dissolved in water for the generation of superoxide anion:

$$
\mathrm{O}_{2}+\mathrm{e}^{\prime} \longleftrightarrow \mathrm{O}_{2}^{-}
$$

The reaction (1) results in the formation of hydroxyl radicals, while hydrogen peroxide and superoxide are formed in reactions (2) and (3), respectively. These radicals exhibit a substantial oxidation power. They attack multitudes of organic and biological compounds in their vicinity, including microbial cell wall and all cellular constituents: proteins, lipids, and the DNA [13]. Generation of hydroxyl radicals through the partial oxidation of water is sufficient to kill microorganisms such as bacteria, destroy viruses, and remove alternative organic contaminants from water. The associated cathodic reaction (3) leads to the formation of superoxide species, which also exhibit a strong oxidation power. This results in the decomposition of organic molecules in water and also contributes to microbe elimination [13].

The superoxide species formed as a result of reaction (3) may be reduced at cathodic sites to hydrogen peroxide:

$$
\mathrm{O}_{2}{ }^{-}+2 \mathrm{H}^{+}+\mathrm{e}^{\prime} \longleftrightarrow \mathrm{H}_{2} \mathrm{O}_{2}
$$

The hydroxyl radical species have a very short halflife. They can react with themselves, also resulting in the formation of hydrogen peroxide:

$$
\mathrm{HO}^{*}+\mathrm{HO}^{*} \longleftrightarrow \mathrm{H}_{2} \mathrm{O}_{2}
$$

Like hydroxyl radicals, superoxide and hydrogen peroxide can damage carbohydrates, lipids, and proteins. The property differentiating $\mathrm{H}_{2} \mathrm{O}_{2}$ from these other oxidants is its longer half-life and the ability to readily diffuse into living cells through the cell wall. In fact, it has an approximate half-

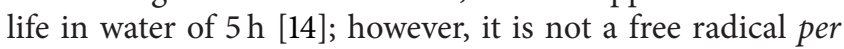
se, for it lacks unpaired electrons. As a result, its reaction rate with many compounds is slow compared to the other true free radicals generated by partial water oxidation [13]. Its conjugate base $\left(\mathrm{HOO}^{-}\right)$is also capable of acting as a reductant. The toxicity of $\mathrm{H}_{2} \mathrm{O}_{2}$ is exacerbated in the presence of ferrous ions or, to a lesser degree, other transitional metal ions such as cuprous ion $\left(\mathrm{Cu}^{+}\right)$.

The chemistry associated with the reactivity of oxide semiconductors and water is complex. Theoretically, the reaction mechanism and the associated charge transfer may be modified by a change in the chemical affinity of electrons or ionisation potential. These quantities are closely related to the Fermi level, $E_{F}$ (a measure of the chemical potential of electrons), for the outermost surface layer of the semiconductor. Although the surface has different properties from the interior (bulk) of the solid, it is not isolated from the bulk. Therefore, the determination of both surface and bulk semiconducting properties is crucial in better understanding of the reactivity of $\mathrm{TiO}_{2}$ with water and the associated photocatalytic properties [12].

\section{Performance-Related Properties}

Conversion of solar energy into chemical energy by oxide semiconductors is a complicated process and involves several steps, including light-induced ionisation, charge separation, charge transport, charge transfer, and both anodic and cathodic reactions. Then the total efficiency of the conversion depends on the efficiencies of all these individual steps. Identification of specific material properties that impact directly on each step is a crucial task leading to improvement of photocatalytic performance. This section considers these performance-related properties as well as the research strategy in the development of high-performance photocatalysts.

Titanium dioxide is able to absorb only a small part of the solar spectrum which is represented in Figure 1. Specifically, the related energy threshold is associated with the band gap that is equal to $3 \mathrm{eV}$ and $3.2 \mathrm{eV}$ for rutile and anatase, respectively. Consequently, decreasing the band gap is expected to result in better utilisation of solar energy and in an increased number of photo-generated electrons and electron holes. One of the common techniques in band gap modification is doping with aliovalent ions.

The electronic charge carriers, which are formed as a result of light-induced ionisation, have a tendency to recombine. The recombination rate may be reduced by imposition of an electric field within the photon penetration 


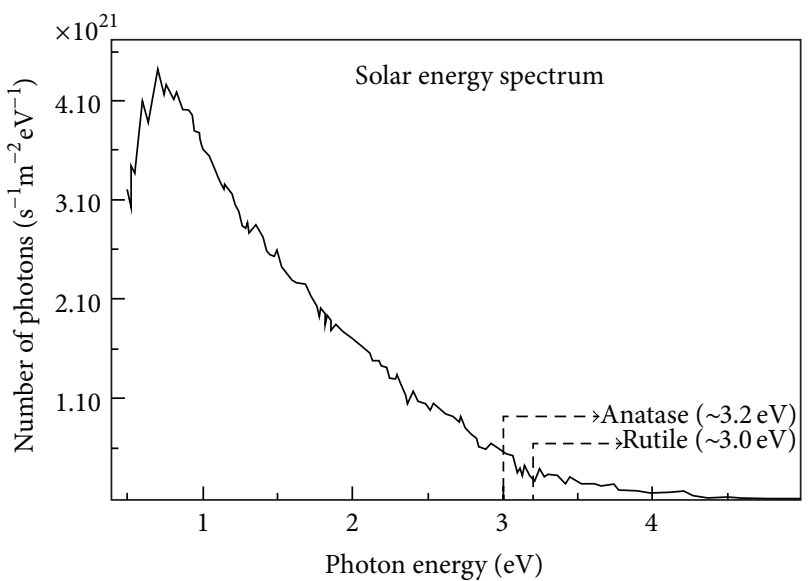

FIGURE 1: The solar spectrum showing parts that can be absorbed by rutile and anatase.

layer, resulting in charge separation. As the photocatalyst operates in aqueous solution, such an electric field is formed spontaneously in the vicinity to the solid/liquid interface. Additionally, any concentration gradient of charged species also generates an internal electric field. As a result of segregation, the chemical composition of the surface layer is different than that of bulk phase. The resulting concentration gradient depends on the conditions of processing: temperature and oxygen activity in the gas phase and the rate of cooling. Understanding of these effects will provide the knowledge that may help in engineering of an optimised electric field, which is associated with maximised performance.

The electronic charge carriers (electrons and electron holes), which are formed as a result of light induced ionisation, must diffuse from the site of their generation to the reaction sites at the surface. This process is affected by ohmic resistance. Therefore, an improved electronic transport can be achieved by an increase in the concentration of charge carriers and/or their mobilities. A large concentration of electrons or electron holes in wide-gap semiconductors such as $\mathrm{TiO}_{2}$ is usually associated with the presence of the shallow states of intrinsic and extrinsic defects within the band gap. Then, thermal ionisation of these states is sufficient to generate a great number of electronic carriers in the conduction or valence bands even at room temperature. However, the modification of mobility is more complex [15].

The performance of anodic and cathodic sites is determined by the local affinity to electrons and the ability to donate electrons, respectively. These can be considered in terms of both collective and local factors [12].

The collective factor is related to the position of the Fermi level at the surface. This quantity is reflective of the ability of electrons to be accepted or donated. The position of the Fermi level is related to work function, which is defined as the work required for transferring an electron from the Fermi level to infinity. Usually, work function exhibits fluctuations along the surface as it is shown in Figure 2. The local work function values, which are higher or lower than a certain critical value $\left(\phi_{\mathrm{cr}}\right)$, correspond to anodic and cathodic sites,

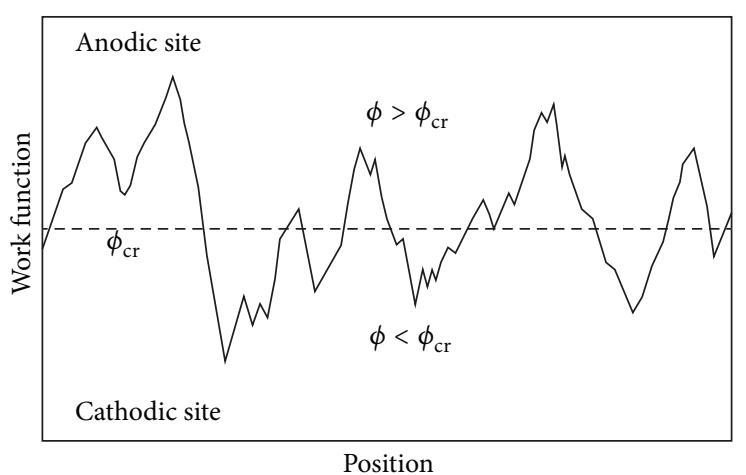

Figure 2: Work function versus position at the surface of a photocatalyst.

respectively. However, the local affinity to electrons and the ability to donate electrons are strongly influenced by the local active sites associated with the charged lattice species and the related local electric field. Typical anodic sites are titanium vacancies, which are strong acceptors of electrons, as well as acceptor-type foreign ions. Typical donor-type sites are oxygen vacancies and titanium interstitials as well as extrinsic additions, such as niobium and tantalum ions. The effective oxidation power for anodic sites is the combination of both collective properties and properties of local active sites. In analogy, the reduction power of cathodic sites should be considered in terms of both collective and local factors.

The anodic and cathodic reactions are represented schematically in the upper part of Figure 3. The local electric fields, represented by band bending, are responsible for the migration of photogenerated electrons (black circle) and electron holes (open circle) to the cathodic and anodic sites, respectively. The progress of the reactions at these sites requires that the electronic charge carriers are transferred across the solid/liquid interface and are available to the adsorbed molecules of water and oxygen, resulting in the generation of hydroxyl radicals and superoxide species, respectively (Figure 3 ). Hence, the charge transfer is the most important reaction step of photocatalytic water purification.

The radical species which are formed at the anodic and cathodic sites have a strong oxidation power. The major oxidants produced are the hydroxyl radical, the superoxide anion, and hydrogen peroxide. These species have the capacity to damage the cell wall. It is important to note, however, that the ability of exogenously generated hydroxyl radicals to damage microorganisms or other organic contaminants depends on the distance of microorganisms from the reaction sites at the photocatalyst surface. When the distance is too large, the radicals have a greater chance to react between themselves. Superoxide and hydrogen peroxide, which are of lower reactivity and longer half-life relative to the hydroxyl radical, can diffuse further from the site of formation and have the ability to penetrate through the cell wall and cell membrane. Once inside the cell, these oxidants can initiate Fenton-like reactions involving transition metal catalysis, such as ferrous ions $\left(\mathrm{Fe}^{2+}\right)$ (Figure 3) [12]. The resulting 


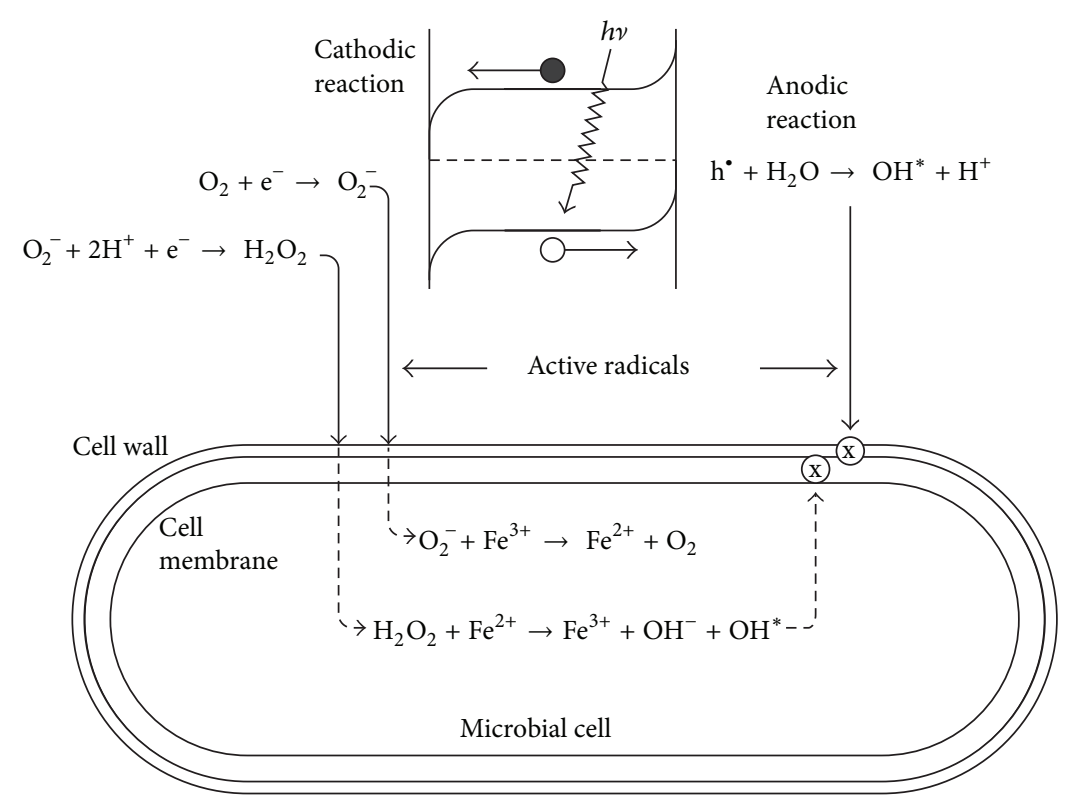

FIGURE 3: The upper part represents anodic and cathodic reactions at the surface of semiconducting photocatalysts leading to the formation of active radicals in water. The lower part represents the interaction between these radicals and the microbial cell.

hydroxyl species, formed in vivo, have greater capacity to damage the cell and are toxic to all waterborne pathogens.

Each of the performance-related properties such as band gap, electrical conductivity, flat band potential, or concentration of surface active sites can be modified by an appropriate processing procedure. The change of each of these properties affects one or more elementary steps of the overall water oxidation reaction. However, the properties themselves are interrelated. Processes aimed at the improvement of one property may lead to deterioration of others. Past studies on the processing of $\mathrm{TiO}_{2}$ with enhanced performance commonly aimed at reducing the band gap. In many instances, this approach may result in the formation of an insulating system in which the charge transport is blocked. Other approaches also include imposition of chemically induced electric fields using the phenomena of diffusion and segregation.

Reduction of the width of band gap to the level that allows an enhanced light absorption could lead to the development of high-performance photocatalysts. A common method is the incorporation of aliovalent ions, which can result in the formation of mid-gap levels and a reduction of the effective energy gap required for light-induced ionisation [16]. This approach leads to an effective increase in photocatalytic activity only when the additional performance-related properties do not play a dominant role.

An essential issue is related to the effect of recombination. It can be reduced by enhancing the charge separation, by imposition of chemically induced electric fields at the interface of $\mathrm{TiO}_{2}$ and water [17]. The phenomenon of segregation can be used as a technology for imposition of these electric fields. The light-induced electrons and holes, which are formed within the light penetration distance, must travel to the surface in order to be involved in photoreactions as expressed by the reactions (1) and (3). High performance requires that these charge carriers are transported rapidly. This can be achieved by imposition of electronic charge compensation regime [17].

Efficient water oxidation, leading to the formation of the active radicals, is possible when the reactive surface exhibits optimal concentration of surface active sites for water adsorption and the formation of active complexes that subsequently decompose into active radicals [14]. Obviously, the quantity of free radicals is a critical determinant for the sanitising efficiency of $\mathrm{TiO}_{2}$ materials. Establishment of assays for measuring free radicals will facilitate the development of photocatalytic apparatus.

\section{Measurement of Free Radicals}

The quantification of free radicals presents a significant challenge, because of their instability and short half-life. For example, the reaction rate constant of the hydroxyl radical with DNA is $10^{8} \mathrm{Mol}^{-1} \mathrm{~S}^{-1}$, and its half-life is in nanoseconds [18]. Therefore, indirect analysis using selective probe molecules, which fluoresce or display other measurable characteristics upon being oxidised, must be employed [19, 20].

From the views of both engineering and biology, it is important to measure the concentrations of the key radicals generated by $\mathrm{TiO}_{2}$ materials. Hydroxyl radical level can be monitored by using dyes, such as 30-(p-hydroxyphenyl) fluorescein (HPF) or $3^{\prime}$-(p-aminophenyl)fluorescein (APF), which are oxidized by $\mathrm{OH}^{\bullet}$ with high specificity (Figure 4) $[21,22]$.

Hydrogen peroxide is a thermodynamically powerful oxidant. Interestingly, it is formed in living organisms during the course of normal metabolism, such as ATP generation in 


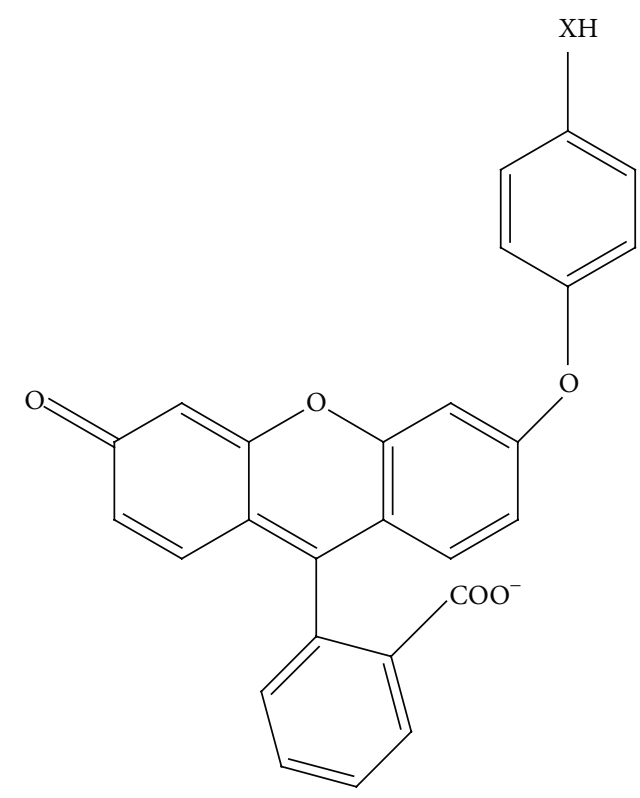

Almost nonfluorescent

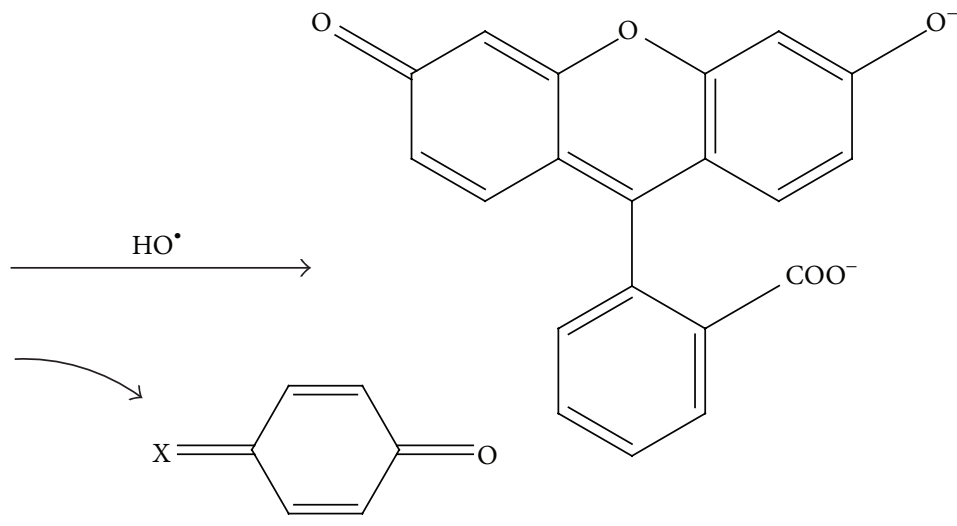

Highly fluorescent

FIgURE 4: Illustration of chemistry for HPF/APF in hydroxyl quantification. $\mathrm{X}=\mathrm{O}$ for HPF and $\mathrm{X}=\mathrm{NH}$ for APF. Excitation wavelength is $488 \mathrm{~nm}$ and emission is measured with $505-550 \mathrm{~nm}$ filter.

mitochondria and bacterial cell membranes, lipid catabolism, and superoxide dismutation [23-25], and, therefore, bacterial cells have the innate ability to detoxify small quantities of $\mathrm{H}_{2} \mathrm{O}_{2}$. As mentioned earlier, its toxicity can be greatly enhanced by Fenton-like reactions through generation of the hydroxyl radical $[26,27]$. Understandably, the concentration of $\mathrm{H}_{2} \mathrm{O}_{2}$ is proportional to disinfection efficiency in the field of photocatalysis and water treatment. Multiple assay formats are available for the detection of $\mathrm{H}_{2} \mathrm{O}_{2}$, including chemiluminescence, spectrophotometric, electrochemistry, and fluorometric methods [28-31]. In addition, the fluorescent dyes Scopoletin, HPF, and APF are useful in its quantification, with the assistance of a catalyst-horseradish peroxidise. Such assays are suited for high through-put analysis.

Commercial kits for the measurement of $\mathrm{H}_{2} \mathrm{O}_{2}$ are also available, for example, Amplex Red reagent (N-acetyl3, 7-dihydroxyphenoxazine) from Invitrogen [32]. Amplex Red is a colourless substrate that reacts with $\mathrm{H}_{2} \mathrm{O}_{2}$ with a 1:1 stoichiometry to produce highly fluorescent resorufin (excitation/emission maxima $=570 / 585 \mathrm{~nm}$ ). Its chemical reaction is shown in Figure 5. The assay is highly specific and sensitive, with a $\mathrm{H}_{2} \mathrm{O}_{2}$ detection limit of $\sim 5 \mathrm{pM}$, although this has also been reported as being up to $50 \mathrm{nM}$ [31]. Because the stoichiometry of Amplex Red and $\mathrm{H}_{2} \mathrm{O}_{2}$ is $1: 1$, the assay results are linear. Care should be taken in dealing with the Amplex Red dye, which is somewhat unstable. At high concentrations $(50 \mu \mathrm{mol} / \mathrm{L})$ it can be autooxidized and produce $\mathrm{O}_{2}{ }^{--}$and $\mathrm{H}_{2} \mathrm{O}_{2}$. Low concentrations of Amplex Red $(10 \mu \mathrm{mol} / \mathrm{L})$ minimize this problem.

As no single assay is perfect, concomitant use of multiple assays for the reliable measurement of the free radicals of interest would seem expedient. Many methods have been discussed in the literature; however, the fluorophore-based assays described above, namely, those utilising HPF/APF and Amplex Red, would be best for this purpose given their high sensitivity and specificity. Specificity here encompasses selectivity for radicals and accuracy. Because of the short halflife, the ability of a method to measure a reactive oxygen species (ROS) quickly is critical. The portability of an assay is also desirable. The proposed assays meet these criteria and thus are considered suitable for free radical measurement. It is also essential to confirm the portability of photocatalysistreated water by comparing its free radical level to normal clean water.

\section{Analysis of Photocatalysis-Mediated Antimicrobial Activity}

In addition to detecting the presence of the free radicals, the antimicrobial effects of photocatalysis-mediated activity on microbes commonly associated with water contamination should be analysed. As shown in Table 1, there are many microorganisms which could potentially contaminate a water source, including bacteria (Legionella, Coliform Enterobacteriaceae, Vibrio, Shigella, Helicobacter, Clostridium, and Salmonella), protozoans (Cryptosporidium and Giardia), and viruses. Faecal matter, particularly human faecal matter, is the key source of contamination by pathogenic organisms [33-35]. History tells us that one of the great scourges of cities in Europe and North America in the 19th century was outbreaks of waterborne diseases such as cholera and typhoid. Even nowadays, in many parts of the developing world, these serious diseases remain a leading cause of death. Indeed, the WHO reports that mortality due to water associated diseases exceeds 5 million people per year. Of these, over $50 \%$ are 
<smiles>CC(=O)N1c2ccc(O)cc2Oc2cc(O)ccc21</smiles>

Nonfluorescent

Highly fluorescent

FIgURE 5: Scheme of Amplex Red assay for $\mathrm{H}_{2} \mathrm{O}_{2}$ measurement.

TABLE 1: Microorganisms found in contaminated waters.

\begin{tabular}{|c|c|c|c|}
\hline Microorganisms & Orgnismal features & Potential health effects & Sources of contamination \\
\hline Cryptosporidium & $\begin{array}{l}\text { A single-celled } \\
\text { protozoan parasite }\end{array}$ & $\begin{array}{l}\text { Gastrointestinal illness (e.g., diarrhoea, } \\
\text { gastroenteritis, vomiting, cramps) }\end{array}$ & Human and animal faecal waste \\
\hline Giardia lamblia & $\begin{array}{l}\text { A single-celled } \\
\text { protozoan parasite }\end{array}$ & $\begin{array}{l}\text { Gastrointestinal illness (e.g., diarrhoea, } \\
\text { gastroenteritis, vomiting, cramps) }\end{array}$ & Human and animal faecal waste \\
\hline Legionella & $\begin{array}{l}\text { Gram-negative } \\
\text { bacterium }\end{array}$ & $\begin{array}{l}\text { Legionnaire's disease, a type of } \\
\text { pneumonia }\end{array}$ & $\begin{array}{l}\text { Found naturally in water and multiplies in } \\
\text { heating systems }\end{array}$ \\
\hline $\begin{array}{l}\text { Coliforms (including } \\
\text { faecal coliform and } E \text {. } \\
\text { coli) }\end{array}$ & $\begin{array}{l}\text { Gram-negative, } \\
\text { rod-shaped bacteria }\end{array}$ & $\begin{array}{l}\text { Not a health threat in itself; it is used to } \\
\text { indicate whether other potentially } \\
\text { harmful bacteria may be present }\end{array}$ & $\begin{array}{l}\text { Coliforms are naturally present in the } \\
\text { environment, as well as faeces; faecal } \\
\text { coliforms and E. coli only come from human } \\
\text { and animal faecal waste. }\end{array}$ \\
\hline Vibrio & $\begin{array}{l}\text { Gram-negative, } \\
\text { rod-shaped bacteria }\end{array}$ & Gastroenteritis & Human and animal faecal waste \\
\hline Shigella & $\begin{array}{l}\text { Gram-negative, } \\
\text { rod-shaped bacteria }\end{array}$ & Bacillary dysentery or shigellosis & Human and animal faecal waste \\
\hline Helicobacter pylori & $\begin{array}{l}\text { Gram-negative, } \\
\text { spiral-shaped bacteria }\end{array}$ & stomach ulcers & $\begin{array}{l}\text { An emerging water-borne bacterium, } \\
\text { possibly due to human faecal waste }\end{array}$ \\
\hline $\begin{array}{l}\text { Clostridium } \\
\text { perfringens }\end{array}$ & $\begin{array}{l}\text { Gram-positive, } \\
\text { rod-shaped bacteria }\end{array}$ & $\begin{array}{l}\text { Gastrointestinal illness (e.g., diarrhoea, } \\
\text { cramps) }\end{array}$ & Human and animal faecal waste \\
\hline Enterococci & $\begin{array}{l}\text { Gram-positive, ovoid } \\
\text { or round bacteria }\end{array}$ & Gastroenteritis & Human and animal faecal waste \\
\hline Salmonella & $\begin{array}{l}\text { Gram-negative, } \\
\text { rod-shaped bacteria }\end{array}$ & Gastroenteritis & Human and animal faecal waste \\
\hline Viruses (enteric) & Virus & $\begin{array}{l}\text { Gastrointestinal illness (e.g., diarrhoea, } \\
\text { vomiting, cramps) }\end{array}$ & Human and animal faecal waste \\
\hline
\end{tabular}

microbial intestinal infections, with cholera being the top cause. The question is which microorganism should be used to assess the efficacy of photocatalysts?

Escherichia coli (E. coli) is a Gram-negative, rod-shaped bacterium and a very common contaminating bacterial species in water. It is routinely used as an indicator for faecal contamination in water and a model organism for enteric bacteria. Hence, E. coli is a logical choice of microorganism for evaluation of photocatalysis-mediated water disinfection. Due to the stark variation in cell wall structure of Gram-positive and Gram-negative bacteria, and because cell wall/plasma membrane damage forms a major part of molecular mechanism for photocatalysis-mediated bactericidal activity [9], it is sensible to also include a Grampositive bacterium for analysis. Indeed, Rincón and Pulgarin demonstrated the difference of $\mathrm{TiO}_{2}$-based photocatalytic efficacy between E. coli and the Gram-positive Bacillus sp., with Bacillus being more resistant to the treatment [36]. The Gram-positive Staphylococcus aureus (S. aureus) and Gram-negative E. coli are currently used in our evaluation protocols. Comparison should also be carried out with Legionella, Cryptosporidium, and Giardia lamblia, since previous studies found that these organisms are highly resistant to traditional disinfection practices [37]. Experimental work in this regard was in fact conducted in 2009 by Navalon et al. and demonstrated that waters containing Cryptosporidium parvum and Giardia lamblia at low concentrations can be efficiently disinfected in continuous flow by using a commercial fibrous ceramic $\mathrm{TiO}_{2}$ photocatalyst [38].

Confocal fluorescence microscopy can also be employed in the evaluation process. The fluorophore propidium iodide 
(PI), for example, could be used to indicate biocidal effectiveness, as the membranes of viable cells are impermeable to PI. Membrane-compromised or dead bacteria, however, would allow entry of the dye which strongly binds to DNA. In contrast, SYTO green-fluorescent dyes such as SYTO 9 (Invitrogen) can enter both living and dead cells. Therefore, simultaneous usage of the two dyes is highly informative in quantifying dead and healthy bacterial cells. Note that a flow cytometer could be used for sample analysis in the place of a confocal microscope if only cell counting is sought. The advantage of the microscopy is to obtain additional structural cellular details. In addition, an antibiotic, such as Ampicillin, should be used as a positive control when determining photocatalysis-mediated biocidal activity.

According to the photocatalytic disinfection mechanism proposed by Sunada et al. [9], using E coli, the free radicals generated upon irradiation of the semiconductor particles caused bacterial inactivation via partial decomposition of the external cell wall and membrane. This is widely accepted. However, the exact kinetics are determined by the surface area of semiconductor, the level of photon absorption, the degree of microbial contamination, and ultimately the quantity of free radicals. Different microbes have different external structures and therefore should exhibit diverse inactivation kinetics under a given photocatalytic condition.

Bacterial cells readily develop resistance to antibiotics, particularly following repeated and inappropriate use. Such resistance presents a major health problem. In light of the potential biocidal activity of photocatalysis, it becomes important to ask: do bacteria develop resistance to photocatalysis-mediated antimicrobial activity? If so, is the level of resistance the same as that for conventional antibiotics? These questions have not yet been asked in this area, because this technique is not widely applied in practice. We speculate that resistance to photocatalysis-generated free radicals will be less than that for antibiotic drugs, since free radical-induced cell death is the primary mechanism of photocatalysis water disinfection rather than being secondary after the effect of antibiotics. However, we need to engage the topic and investigate it. An experiment can be designed by working on a population of $E$. coli for a number of continuous photocatalytic treatment-survival analysis cycles. If the survival rates are increasing along the exposure treatments, then the resistance will be a problem. Any such resistance mechanism observed should be keenly studied.

\section{Difference between Photocatalysis and Antibiotics}

Kohanski et al. [39] recently demonstrated that the three major classes of bactericidal antibiotics all stimulate the production of highly deleterious hydroxyl radicals in Gramnegative and Gram-positive bacteria, which ultimately leads to cell death by inducing oxidative DNA and protein damage. This is regardless of their known modes of action, be it targeting protein synthesis, DNA replication and repair, and cell wall homeostasis. Both Escherichia coli and Staphylococcus aureus, under the treatment of bactericidal antibiotics, were shown to produce hydroxyl free radicals. Given the radical formation of photocatalysis, these findings give promise to the application of photocatalysis-mediated water disinfection.

A UV source and $\mathrm{a} \mathrm{TiO}_{2}$ appliance are the basic requirements for photocatalysis-mediated water disinfection, applicable to remote areas that lack potable water. This also complements the current drinking water treatment consisting of a series of systems for coagulation and flocculation, filtration, and oxidation with chlorine [40]. Drinking water is not sterile, however. Bacteria can be found in the distribution system and at the tap. Most of these organisms are harmless, but some opportunist pathogens such as Pseudomonas aeruginosa and Aeromonas spp. may multiply during distribution, given suitable conditions. Currently there is some debate as to whether these organisms are responsible for any waterborne, gastrointestinal disease in the community but $P$. aeruginosa is known to cause infections in immunocompromised patients and weakened patients in hospitals. The contamination of drinking water by pathogens causing diarrhoeal disease is the most important aspect of drinking water quality.

\section{Future Prospects}

The engineering and understanding of semiconductor photocatalyst $\mathrm{TiO}_{2}$ will continue to advance. Its large scale application in water disinfection is a matter of when, not if. Despite the intensive research of the past decades, desirable photocatalytic efficacy is yet to be achieved to a level suitable for practical applications. The reality is that access to clean water is still a major problem in many parts of the world. The seventh cholera pandemic, since it was started in 1961, arrived in South America in 1991 and caused 4700 deaths in one year [41]. Photocatalysis-based water sanitisation will play a major role in people's daily lives. Such a reality is not too far away, as the usage of $\mathrm{TiO}_{2}$ has been widely applied to the other industries, including examples such as self-cleaning automobiles with a layer of $\mathrm{TiO}_{2}$ paint. Undoubtedly, it is the future breakthrough in technology and engineering that will turn photocatalysis into a driving force for maintaining critical water resources.

\section{Conclusions}

Photocatalysis is undoubtedly a desirable tool in dealing with microbial contamination of drinking water sources. Much remains to be done in terms of maximising its efficiency, by enhancing the performance-related properties of oxide materials for photocatalytical oxidation of organic contaminants in water. Future work should be focused on optimisation of these properties through material design and engineering. There is an urgent need to have a concerted approach from free radical measurement to antimicrobial assessment.

\section{Conflict of Interests}

The authors declare that there is no conflict of interests regarding the publication of this paper. 


\section{References}

[1] Y. Liu, J. Li, X. Qiu, and C. Burda, "Novel $\mathrm{TiO}_{2}$ nanocatalysts for wastewater purification: tapping energy from the sun," Water Science and Technology, vol. 54, no. 8, pp. 47-54, 2006.

[2] T. Tachikawa, S. Tojo, K. Kawai et al., "Photocatalytic oxidation reactivity of holes in the sulfur- and carbon-doped $\mathrm{TiO}_{2}$ powders studied by time-resolved diffuse reflectance spectroscopy," The Journal of Physical Chemistry B, vol. 108, no. 50, pp. 1929919306, 2004.

[3] R. Asahi, T. Morikawa, T. Ohwaki, K. Aoki, and Y. Taga, "Visible-light photocatalysis in nitrogen-doped titanium oxides," Science, vol. 293, no. 5528, pp. 269-271, 2001.

[4] S.-H. Lee, S. Pumprueg, B. Moudgil, and W. Sigmund, "Inactivation of bacterial endospores by photocatalytic nanocomposites," Colloids and Surfaces B: Biointerfaces, vol. 40, no. 2, pp. 93-98, 2005.

[5] R. Nakamura and Y. Nakato, "Molecular mechanism of water oxidation reaction at photo-irradiated $\mathrm{TiO} 2$ and related metal oxide surfaces," Diffusion and Defect Data B: Solid State Phenomena, vol. 162, pp. 1-27, 2010.

[6] A. Fujishima, X. T. Zhang, and D. A. Tryk, " $\mathrm{TiO}_{2}$ photocatalysis and related surface phenomena," Surface Science Reports, vol. 63, no. 12, pp. 515-582, 2008.

[7] M. Cho, H. Chung, W. Choi, and J. Yoon, "Linear correlation between inactivation of $\mathrm{E}$. coli and $\mathrm{OH}$ radical concentration in $\mathrm{TiO}_{2}$ photocatalytic disinfection," Water Research, vol. 38, no. 4, pp. 1069-1077, 2004.

[8] D. M. A. Alrousan, M. I. Polo-López, P. S. M. Dunlop, P. Fernández-Ibáñez, and J. A. Byrne, "Solar photocatalytic disinfection of water with immobilised titanium dioxide in recirculating flow CPC reactors," Applied Catalysis B: Environmental, vol. 128, pp. 126-134, 2012.

[9] K. Sunada, T. Watanabe, and K. Hashimoto, "Studies on photokilling of bacteria on $\mathrm{TiO}_{2}$ thin film," Journal of Photochemistry and Photobiology A: Chemistry, vol. 156, no. 1-3, pp. 227233, 2003.

[10] C. Navntoft, P. Araujo, M. I. Litter et al., "Field tests of the solar water detoxification SOLWATER reactor in Los Pereyra, Tucumán, Argentina," Journal of Solar Energy Engineering, vol. 129, no. 1, pp. 127-134, 2007.

[11] J. Gamage and Z. Zhang, "Applications of photocatalytic disinfection," International Journal of Photoenergy, vol. 2010, Article ID 764870, 11 pages, 2010.

[12] J. Nowotny, Oxide Semiconductors for Solar Energy Conversion: Titanium Dioxide, CRC Press, Boca Raton, Fla, USA, 2012.

[13] N. J. Sucher, M. C. Carles, J. Nowotny, and T. Bak, "Photocatalytic water disinfection on oxide semiconductors: part 2-structure, functional properties and reactivity of microbial agents," Advances in Applied Ceramics, vol. 111, no. 1-2, pp. 1633, 2012.

[14] J. Nowotny, T. Bak, M. K. Nowotny, and L. R. Sheppard, " $\mathrm{TiO}_{2}$ surface active sites for water splitting," Journal of Physical Chemistry B, vol. 110, no. 37, pp. 18492-18495, 2006.

[15] F. M. Hossain, A. V. Evteev, I. V. Belova, J. Nowotny, and G. E. Murch, "Structural, electronic and optical properties of titania nanotubes," Advances in Applied Ceramics, vol. 111, no. 1-2, pp. 72-93, 2012.

[16] K. Wilke and H. D. Breuer, "The influence of transition metal doping on the physical and photocatalytic properties of titania," Journal of Photochemistry and Photobiology A: Chemistry, vol. 121, no. 1, pp. 49-53, 1999.
[17] T. Bak, J. Nowotny, N. J. Sucher, and E. Wachsman, "Effect of crystal imperfections on reactivity and photoreactivity of $\mathrm{TiO}_{2}$ (Rutile) with oxygen, water, and bacteria," The Journal of Physical Chemistry C, vol. 115, no. 32, pp. 15711-15738, 2011.

[18] W. H. Glaze and J. W. Kang, "Advanced oxidation processes for treating groundwater contaminated with TCE and PCE: laboratory studies," Journal-American Water Works Association, vol. 88, no. 5, pp. 57-63, 1988.

[19] J. M. Burns, W. J. Cooper, J. L. Ferry et al., "Methods for reactive oxygen species (ROS) detection in aqueous environments," Aquatic Sciences, vol. 74, no. 4, pp. 683-734, 2012.

[20] O. C. Zafiriou, N. V. Blough, E. Micinski, B. Dister, D. Kieber, and J. Moffett, "Molecular probe systems for reactive transients in natural waters," Marine Chemistry, vol. 30, no. 1-3, pp. 45-70, 1990.

[21] K. Setsukinai, Y. Urano, K. Kakinuma, H. J. Majima, and T. Nagano, "Development of novel fluorescence probes that can reliably detect reactive oxygen species and distinguish specific species," The Journal of Biological Chemistry, vol. 278, no. 5, pp. 3170-3175, 2003.

[22] C. A. Cohn, S. R. Simon, and M. A. A. Schoonen, "Comparison of fluorescence-based techniques for the quantification of particle-induced hydroxyl radicals," Particle and Fibre Toxicology, vol. 5, no. 1, article 2, 2008.

[23] I. Fridovich, "Superoxide radical and superoxide dismutases," Annual Review of Biochemistry, vol. 64, pp. 97-112, 1995.

[24] J. M. McCord and I. Fridovich, "Superoxide dismutase: the first twenty years (1968-1988)," Free Radical Biology and Medicine, vol. 5, no. 5-6, pp. 363-369, 1988.

[25] G. Gille and K. Sigler, "Oxidative stress and living cells," Folia Microbiologica, vol. 40, no. 2, pp. 131-152, 1995.

[26] H. J. H. Fenton, "LXXIII.-Oxidation of tartaric acid in presence of iron," Journal of the Chemical Society, Transactions, vol. 65, pp. 899-910, 1894.

[27] S. Goldstein, D. Meyerstein, and G. Czapski, "The Fenton reagents," Free Radical Biology \& Medicine, vol. 15, no. 4, pp. 435-445, 1993.

[28] R. J. Kieber and G. R. Helz, "Two-method verification of hydrogen peroxide determinations in natural waters," Analytical Chemistry, vol. 58, no. 11, pp. 2312-2315, 1986.

[29] J. T. Corbett, "The scopoletin assay for hydrogen peroxide. A review and a better method," Journal of Biochemical and Biophysical Methods, vol. 18, no. 4, pp. 297-307, 1989.

[30] L. A. Marquez and H. B. Dunford, "Transient and steadystate kinetics of the oxidation of scopoletin by horseradish peroxidase compounds I, II and III in the presence of NADH," European Journal of Biochemistry, vol. 233, no. 1, pp. 364-371, 1995.

[31] S. Watabe, Y. Sakamoto, M. Morikawa, R. Okada, T. Miura, and E. Ito, "Highly sensitive determination of hydrogen peroxide and glucose by fluorescence correlation spectroscopy," PLoS ONE, vol. 6, no. 8, Article ID e22955, 2011.

[32] M. Zhou, Z. Diwu, N. Panchuk-Voloshina, and R. P. Haugland, "A stable nonfluorescent derivative of resorufin for the fluorometric determination of trace hydrogen peroxide: applications in detecting the activity of phagocyte NADPH oxidase and other oxidases," Analytical Biochemistry, vol. 253, no. 2, pp. 162$168,1997$.

[33] World Health Organization, Guidelines for Drinking-water Quality, Incorporating 1st and 2nd Addenda, Volume 1, Recommendations, WHO, Geneva, Switzerland, 3rd edition, 2008. 
[34] A. Fenwick, "Waterborne infectious diseases-could they be consigned to history?" Science, vol. 313, no. 5790, pp. 1077-1081, 2006.

[35] J. P. S. Cabral, "Water microbiology. Bacterial pathogens and water," International Journal of Environmental Research and Public Health, vol. 7, no. 10, pp. 3657-3703, 2010.

[36] A.-G. Rincón and C. Pulgarin, "Use of coaxial photocatalytic reactor (CAPHORE) in the $\mathrm{TiO}_{2}$ photo-assisted treatment of mixed E. coli and Bacillus sp. and bacterial community present in wastewater," Catalysis Today, vol. 101, no. 3-4, pp. 331-344, 2005.

[37] S. Regli, "Disinfection requirements to control for microbial contamination," in Regulating Drinking Water Quality, C. E. Gilbert and E. J. Calabrese, Eds., Lewis, Chelsea, Mich, USA, 1992.

[38] S. Navalon, M. Alvaro, H. Garcia, D. Escrig, and V. Costa, "Photocatalytic water disinfection of Cryptosporidium parvum and Giardia lamblia using a fibrous ceramic $\mathrm{TiO}_{2}$ photocatalyst," Water Science and Technology, vol. 59, no. 4, pp. 639-645, 2009.

[39] M. A. Kohanski, D. J. Dwyer, B. Hayete, C. A. Lawrence, and J. J. Collins, "A common mechanism of cellular death induced by bactericidal antibiotics," Cell, vol. 130, no. 5, pp. 797-810, 2007.

[40] J. Fawell and M. J. Nieuwenhuijsen, "Contaminants in drinking water: environmental pollution and health," The British Medical Bulletin, vol. 68, no. 1, pp. 199-208, 2003.

[41] P. R. Reeves and R. Lan, "Cholera in the 1990s," British Medical Bulletin, vol. 54, no. 3, pp. 611-623, 1998. 

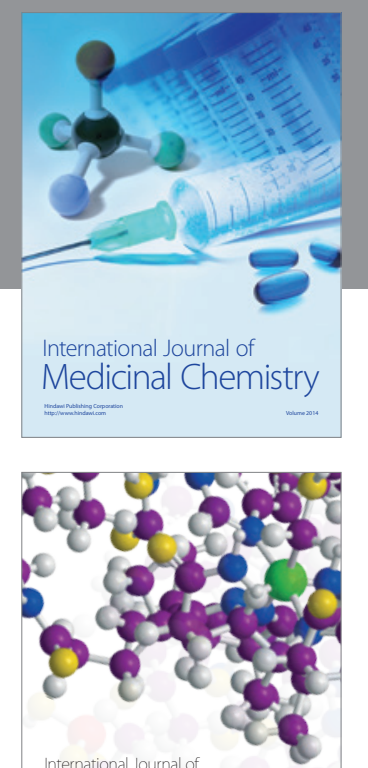

\section{Carbohydrate} Chemistry

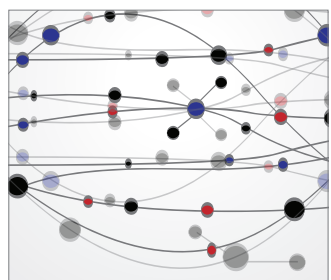

The Scientific World Journal
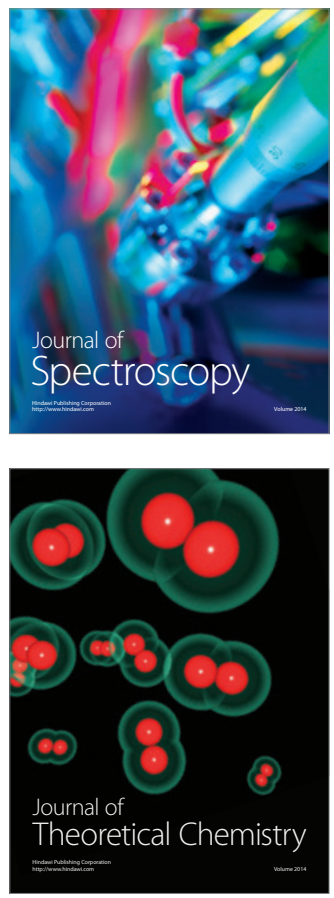
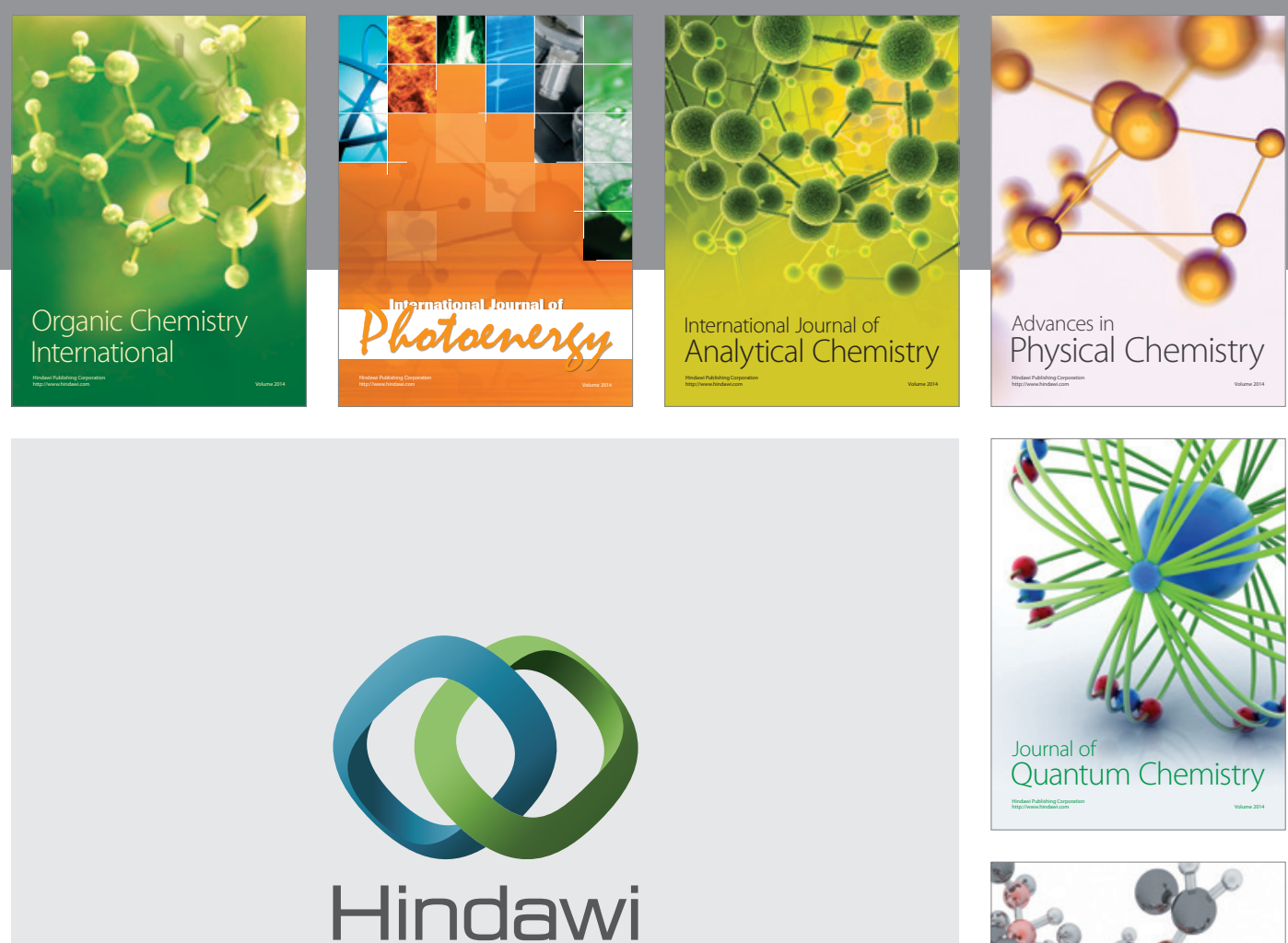

Submit your manuscripts at

http://www.hindawi.com

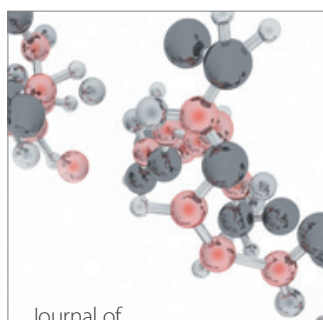

Analytical Methods

in Chemistry

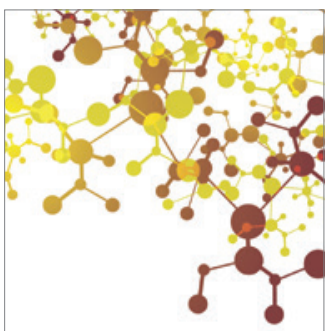

Journal of

Applied Chemistry

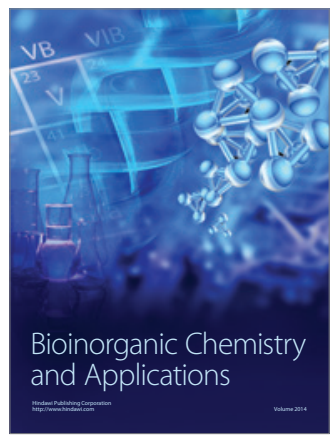

Inorganic Chemistry
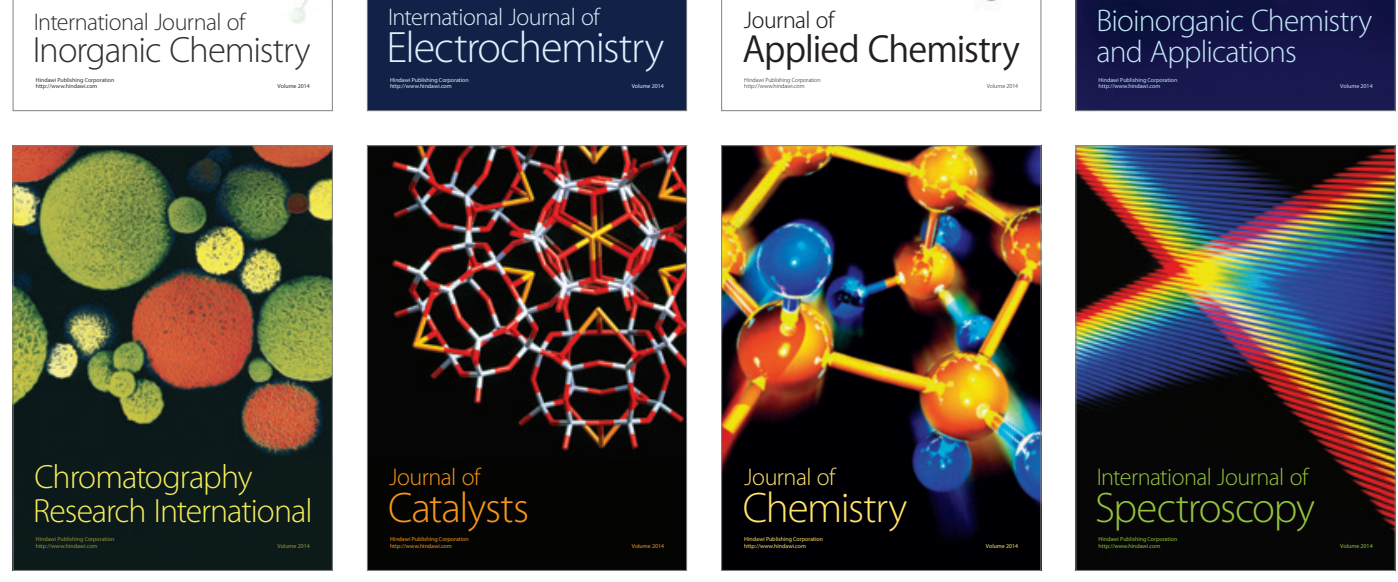